\title{
Fenilcetonuria asociada a craneostenosis y fisura palatina
}

\author{
"Dres.: C. Noziglia del N.," J. Contreras A., y **Q.F.L. Arévalo F.
}

\begin{abstract}
A baby male, product of a nomal pregnancy with 38 weeks gestation and a birth weight of $2600 \mathrm{~g}$ was studied.

When 2 months old he was brought into the hospital because of a bronchopneumoria. On physical examination on entry into hospital it was funnd thet he had a cleft palate, microcephaly, white skin and black hair and a generalizad dematibs.

Cranial X-hays confirmed the existunce of a cranium stenosis and the ferric chloride test as al so the aminoa. cid chromatography in blond and urine permited a diagnosis of phenylketonuria.

He was treated with a diet of $1,2 \mathrm{~g} / \mathrm{kg} / \mathrm{day}$ of proteins, there not being to hand special milk formula.

He died after being operated on for his tanium stenosis.
\end{abstract}

La fenilcetonuria es una enfermedad metabólica de los aminoácidos aromáticos. Es una enfermedad hereditaria- transmisible en forma autosómica recesiva. ${ }^{9} \mathrm{La}$ incidencia en caucásicos es de 1 en 20.000 habitantes. 9

Patogenia: en sujetos nonnales la fenilalanina es convertida a tirosina en el hígado por la fenilalanina hidroxilasa. ${ }^{8}$ En los homocigotos para la fenilcetonuria clásica no hay actividad de esta enzima y la fenilalanina en sangre aumenta de 30 a $100 \mathrm{mg} \%$, ya a las 2 ó 3 semanas de vida.

Existen recién nacidos en los cuales hay un retardo de la maduración enzimática; en general prematuros, con fenilalaninemia elevada transitoriamente.

La actividad de la fenilalanina hidroxilasa en otros casos puede estar disminuida entre $1 / 2$ y 1/10 de lo nomal, dando hiperfenilalaninemia moderada sin fenilcetonuria. ${ }^{\$}$

Clinica: retardo mental severo, con C.I. de 30 o menos, frecuentemente ojos azules, piel clara, eczema, microcefalia, convulsiones, atetosis, hipertonicidad e hiperreflexia, ${ }^{4,9}, 9$

Los niños fenilcetonúricos no tienen daño cerebral al nacer y sólo lo adquieren al ingerir fenilalanina.

\section{CASO CLIVICO}

Lactunte menor, sexo masculino, nacido el 4 de marzo de 1977, en la Maternidad del Hospital Gustavo Fricke de Viñadel Mar, con peso al nacer de 2.600 g y Apgar 9 al minuto; producto de embarazo nomal, controladode 38 semanas de gestación, primípara de 18 años sin fenilcetonuria, con fenilalaninemia normal.

\footnotetext{
*Servicuo de Pediatria Hospital Gustavo Frickc, Viña del Mar
} **Laljoratorio Clínicu Hospital Carlos Van Buren. Valparaiso.
Hospitalizado por primera vez en la Unidad de R.N., descle las 6 hrs. de vida hasta los 10 días de edad por ictericia fisiológica, fisura palatina y rinitis purulenta a Pseudomona, secundaria a sonda nasogástrica colocada por gran dificultad para alimentarse.

Hospitalizado por segunda vez el 22 de abril, al mes 18 dlas de edad, durante 11 días por diarrea aguda con deshidratación, desnutrición, otitis media supurada, fisura palatina y craneostenosis.

Tercera hospitalización el 5 de mayo a los 2 meses de edad, por bronconeumonía, desnutrición, fisura, palatina, craneostenosis y dermatitis seborreica.

Al examen físico llaman la atención los siguientes hechos: * piel blanca, pelo negro, ojos café, dermatitis seborreica generalizada, rebelde a tratamientw, bregma cerrado con sutura sagital ligeramente solevantada y alargamiento anteroposterior de la cabeza, CC máxima de $35 \mathrm{~cm}$, fisura palatina, hipertonía muscular generalizada e hiperreflexia profunda, Moro y marcha espásticos.*

Hemograma, orina, líquido cefalorraquideo, protromgina normales. Grupo sanguíneo $\mathrm{A}_{2} \mathrm{Rh}(+)$

VDRL (-)

Rx Tórax nomal.

$\mathrm{H}_{x}$ Cráneo:** deformación de cráneo compatible con dolicucefalia.

Interconsulta a Neurocinugia: confirma craneotenosis de indicación operatoria (escafocetalia).

Fondo de ojo: Papilas de color, forma y límites normales. Coloración de la retina nonnal, excepto en partes superiores que están de color blanquecino grisáceo. Si. gue sólo ocasionalmente la luz y se distrae. No se puede establecer aún si hay o no visión.

Test cloruro férrico en orina: intensamente positivo.

Cromatografia* en sangre y en orina, muestran fenilalanina muy elevada.

Evolución y tratamiento: evolución con curva de peso plana durante 2 meses, no creciendo la circunferencia craneana y haciéndose cada vez más manifiesta la hipertonía, hiperflexía y daño cerebral.

El tratamiento dietéticu se realizó con un aporte total de $1,2 \mathrm{~g} / \mathrm{kg} / \mathrm{dia}$ de proteínas, más un agregado de grasas e hidratos de carbono que aportaba un total de $250 \mathrm{cal} / \mathrm{kg} /$ día, por no disponer de elementos dietéticos con poxa renilalanina. Aporte de penilalanina $=65 \mathrm{mg} / \mathrm{kg} / \mathrm{d}$ ía. 
Se traslada a Neurocirugía donde se interviene el dia 26 de julio, talleciendo a las 2 hrs. de la operación, a los 4 $1 / 2$ meses de vidu.

El informe de autopsia no reveló otras malformaciones.

\section{COMENTARIO}

En países desarrollados como Gran Bretaña y U.S.A., la búsqueda de alguras enfermedades metabólicas, entre ellas la fenilcetonuria, se efectúa mediante screening test en todos los recién nacidos en fonna dirigida y precoz entre el $4 .{ }^{\circ} y$ $100^{\circ}$ días de vida, con lo cual se logra pesquisar el total de los casos. ${ }^{\perp}$

Al nacer el nin̄o no tiene daño cerebral y éste sólo se produce al introducir la fenilalanina en la dieta.". Si el tratamiento se inicia en el período neonatal, el cerebro debe desarrollarse normalmente; si el tratamiento se inicia después de algunas semanas, el C.I. tiende a ser menor; si el tratamiento se inicia después de los 6 meses de edad, a menudo se observa una leve mejorfa del C.I., pero el paciente permanecerá con retardo mental. ${ }^{y}$

Para hacer dg precoz se dispone del test de Guthrie. ${ }^{5,6,7}$ Consiste en la inhibición del desarrollo del bacilo subtilis, por medio de un antagonista de la fenilalanina, la betionilalanina. Si la fenilalanina en sangre está elevada, la inhibición no se produce y se desarrolla la bacteria. La sensibilidad del test detecta niveles de fenilalanina sobre $4 \mathrm{mg} \%$.

El test del cloruro férrico $0^{\theta}$ en orina con viraje a verde, nos indicaría la posibilidad de uno de los siguientes errores del metabolismo: fenilcetonuria, tirosinemia histidinemia, malabsorción de metionina o enfermedad de jarabe de arce. Tiene el inconveniente que no detecta hiperfenilalaninemia sin fenilcetonuria, por lo tanto no es útil en el período de recién nacido.

Phenistix: ${ }^{8}$ el test consiste en el cambio de coloración a verde en un pañal mojado con orina del enfermo. Tiene el mismo inconveniente que el test del cloruro férrico que no detecta hiperfenilalaninemia sin fenilcetonuria.

La confimación diagnóstica se establece mediante cromatografía en sangre, orina y L.C.R., y determinación cuantitativa de fenilalanina en sangre. ${ }^{8,9}$ Fenilalaninemia normal $=0,6$ a 1,45 $\mathrm{mg} \%$. Hiperfenilalaninemia $=5$ a $20 \mathrm{mg} \%$. Para que aparezca fenilalanina y sus inetabolitos en la orina, la fenilalanina en sangre debe estar en niveles entre 10 y $20 \mathrm{mg} \%$. $^{\mathrm{s}}$
Tratamiento: consiste en reducir la ingesta de fenilalanina a niveles que prevengan la hiperfenilalaninemia ${ }^{y}$ manteniéndola en niveles de 4 a 8 $\mathrm{mg} \%$, lo que se logra con un aporte de más o menos $50 \mathrm{mg} / \mathrm{kg} /$ día de fenilalanina. Esta dieta se suplementa con hidratos de carbono, grasas, fruta y polivitamínicos.

El tratamiento dietético estricto debe mantenerse hasta los 5 ó 7 años $^{*} y$ posteriormente la ingesta de proteínas debe ser pobre.

La hiperfenilalaninemia de la embarazada daña el cerebro del feto, por lo tanto el tratamiento de ésta debe ser riguroso, manteniendo niveles de fenilalanina plasmática de 6 a $8 \mathrm{mg}^{\circ}{ }^{9}$

Embarazadas con hiperfenilalaninemia tienen mavor incidencia de hijos con malformaciones congénitas, como microcefalia y defectos cardia$\operatorname{cos.9}$ También se describen abortos a repetición y niños pequeños para la edad de gestación. ${ }^{\theta}$

En los niños con fenilcetonuria se describe la microcefalia, pero no hemos encontrado comunicada la craneostenosis ni la fisura palatina en la literatura a nuestro alcance, motivo por el cual hemos creído de interés la presentación de este caso clínico.

\section{RESUMEN}

Se presenta un lactante, sexo masculino, producto de un embarazo normal, con 38 semanas de gestación y peso de RN de $2600 \mathrm{~g}$.

A los 2 meses es hospitalizado por una bronconeumonia. En su examen físico de ingreso llama la atención la existencia de fisura palatina, microcefalia, piel blanca con pelo negro $y$ dermatitis seborreica generalizada.

La radiografia de cráneo confirma la existencia de una craneostenosis y el test de cloruro férrico así como la cromatografía de aminoácidos de sangre y orina permiten establecer el diagnóstico de fenilcetonuria.

Se trata con una dieta con $1,2 \mathrm{~g} / \mathbf{k g} /$ día de proteínas por no disponer de fómula láctea especial.

Fallece luego de ser operado de su craneostenosis.

\section{REFERENCLAS}

IStarfietd, B. and Holtzman, N.A.: Efectiveness of PKC screening in United States, United Kingdom and Ireland: The New England Journal of Medicine, 283: 118, 1975.

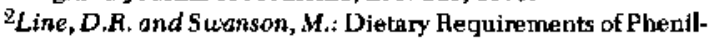
alanina in Infants with Hyperphenylalaninateria: Arch Dis. Child., 48: 648, 1973. 
${ }^{3}$ Faquhar, $J . W$.; Baby of a Phenilketonuric Mother: inferences draen from a single cuse: Arch. Dis. Child., 40: 205, 1974.

${ }^{4}$ Betton, N.R.; Crombie, J.D.; Robins, S.P.; Stephen, R. and Faryuhar. J.W.: Measurement of Phenylalanine in Routine Case of Phenylketonuric Children: Arch. Dis. Child., 48: 472, 1973.

${ }^{5}$ Kennedy, R.: A Single Device for the Rapid Plating of Autoclaved Blood Spots for the Guthrie Test: The Journal of Medical Laboratory Technology, 26; $269,1 \otimes 68$.

${ }^{6}$ Lindsay, G.: Bacterial Inhibition Assays for Phenylketunuria and other Metabolic Disorders: Ann. Clin. Biuchem, 9: 115, 1972

TGuthrie, R. and Susi, A.: A Simple Phenilalanine Method for Detecting Phenylketonuria in Large Populations in Newbom infants: Pediatrics, 32: 338, 1963.

${ }^{8}$ Hutchinson, J.H.: Practical Pediatric Problems. London, Ed. LLOYD - LUKE LTD., 1972.

9 Forfar, J.O., Ameil, G.C.4 Texbook of Paediatrics. Edinburgh and London, Ed. Churchill Livingstone, 1973. 